\title{
The suitability of Finnish climate for fire blight (Erwinia amylovora) epidemics on apple
}

\author{
Mariela Marinova-Todorova, Jukka Ranta, Salla Hannunen \\ Finnish Food Safety Authority Evira, Mustialankatu 3, 00790 Helsinki, Finland \\ e-mail: salla.hannunen@evira.fi
}

\begin{abstract}
Fire blight, which is an important disease of apples and pears, has never been detected in continental Finland. In this study the suitability of the Finnish climate for apple blossom blight infections by Erwinia amylovora was evaluated with the epidemiological model Maryblyt ${ }^{\mathrm{TM}}$. This was done in fourteen locations, and for two apple cultivars differing in flowering times. Climatic conditions were predicted to be suitable for blossom infections in $18-51 \%$ of the years, and the annual period of suitable conditions was predicted to last up to two to five days, depending on the location and apple cultivar. The suitable period was predicted to be longer in some locations in central Finland than in those in the southernmost parts of the country. Based on these results the official surveys that are carried out to confirm the absence of fire blight in Finland cannot be targeted only to some parts of the country.
\end{abstract}

Key words: invasive alien, pathogen, epidemiology, models

\section{Introduction}

Fire blight, caused by the bacterium Erwinia amylovora ((Burrill) Winslow et al.), is an important disease of apples and pears. In susceptible host plants it causes a systemic infection, which can result in symptoms in all plant parts, fruit, leaf, shoot and flower tissue. Finally the infection can lead to death of the entire plant. In addition to pome fruit the bacterium infects various ornamental plants belonging to the family Rosaceae, such as Chaenomeles spp., Amelanchier spp., Crataegus spp., Cotoneaster spp. and Sorbus spp..

E. amylovora was introduced into Europe from North America in the middle of the $20^{\text {th }}$ century (Bonn and van der Zwet 2000). Since then it has spread to most European countries, including the countries neighbouring Finland, i.e. Sweden (Norin 1987), Norway (Sletten 1990), Russia (EPPO 2013) and Estonia (EPPO 2014). In Finland fire blight was detected for the first time in 2014 on Aland (Evira 2014). In continental Finland fire blight has never been detected.

In the EU Plant Health legislation (Council Directive 2000/29/EC) E. amylovora is considered as a harmful organism whose introduction and spread within the community should be prevented. For Finland the EU has granted the status of a protected zone with respect to fire blight, since the disease is not known to be present in Finland. The protected zone status imposes special requirements that aim at preventing the introduction of the disease. The import of fire blight host plants is restricted; the absence of the disease has to be verified by an official survey every year, and if the disease is found it has to be eradicated.

The occurrence of fire blight epidemics depends largely on local weather conditions, and the requirements for infection events and symptom development are well known. Primary infections are usually caused by bacteria disseminated from overwintered cankers to flowers by insects, rain or wind. In the flowers the bacteria multiply and then enter the plant through natural openings at the flower base. The bacteria are transmitted effectively from flower to flower by pollinating insects. A comprehensive description of the disease cycle can be found in e.g. Thomson (2000).

Several epidemiological models for predicting epidemics and symptom development of fire blight have been developed. The most widely used models are CougarBlight (Smith 1993, Smith and Pusey 2011), BIS95 (Billing 1996) and Maryblyt (Steiner 1990a, Steiner 1990b). In areas where E. amylovora is present these models are used to predict infection events and appearance of symptoms in order to facilitate the appropriate timing of control measures (e.g. Bonn and Leuty 1993, Bonn 1996, Bazzi et al. 1996, Lightner et al. 1999, Abol Maatey et al. 2002, Moltmann 2006, Vogelsanger et al. 2006, Bobev and Lightner 2008). Although the models were originally developed to support growers in the control of the disease, they have also been used for assessing the risk of fire blight infections in areas where the disease is not present. CougarBlight has been used to evaluate the probability of fire blight infections in Estonia (Kõiva 2003), BIS95 has been used for preparing a pest risk assessment for Norway (Sletten and Rafoss 2007), and Maryblyt has been used to assess the potential of $E$. amylovora to cause infections in Argentina (Giayetto and Rossini 2011).

Manuscript received January 2015 
The aim of this study was to evaluate the suitability of the Finnish climate for apple blossom blight infections by Erwinia amylovora with epidemiological modelling. The evaluation was done for fourteen geographical locations around the country, and for two apple cultivars differing in blooming times. The results can be used for assessing the risk of fire blight in Finland and for targeting the yearly official surveys that aim for early detection of possible introductions.

\section{Material and methods}

The suitability of the Finnish climate for apple blossom infections by Erwinia amylovora was evaluated based on historical weather data for 20 years (1993 - 2012) from fourteen different geographical locations (Fig. 1).

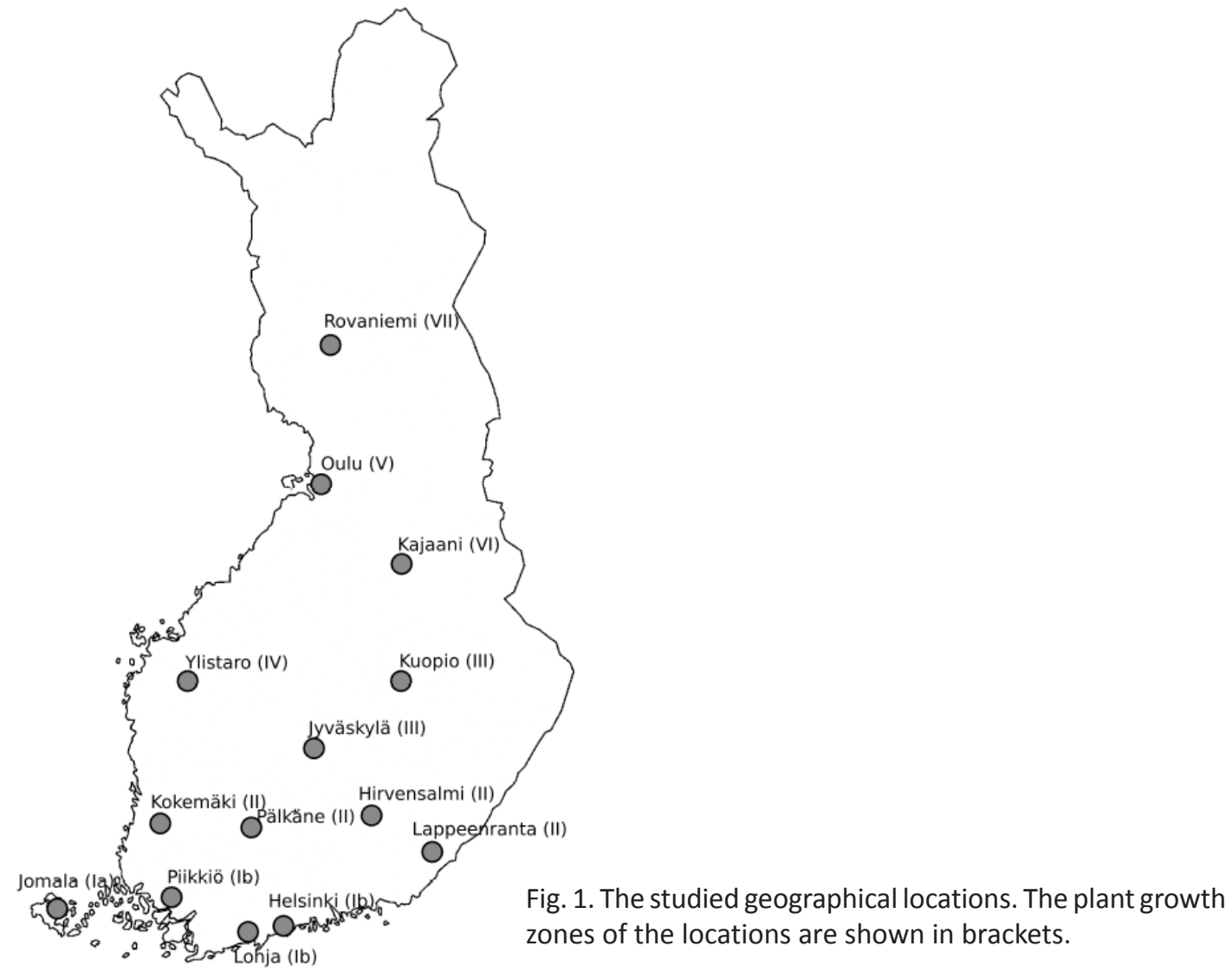

The evaluation was done by using Maryblyt ${ }^{\mathrm{TM}} 7.0$ which is a computer program for predicting infection events and symptom development of fire blight in apples and pears (Steiner 1990a). Maryblyt assumes that for apple blossom infections to occur four requirements have to be met: (1) flowers must be open with stigmas and petals intact, (2) accumulation of at least 110 degree-hours (DH) above $18.3^{\circ} \mathrm{C}$ since the beginning of the bloom, (3) occurrence of dew or rain ( $0.25 \mathrm{~mm}$ during the current day, or $2.5 \mathrm{~mm}$ during the previous day), and (4) daily average temperature of at least $15.6{ }^{\circ} \mathrm{C}$ (Steiner 1990a). Also, Maryblyt assumes that there is an abundance of inoculum in or around the orchard.

Depending on how many of the requirements for blossom infections are met, Maryblyt ranks the risk in four risk levels: "infection" (if all four requirements are met), "high risk" (if three requirements are met), "moderate risk" (if two requirements are met), and "low risk" (if only one requirement is met). 
The studied geographical locations were selected so that all the most important apple production areas and eight of the nine Finnish climatic zones for fruit trees and woody ornamental plants (plant growth zones) were represented (Fig. 1). The represented plant growth zones were Ia, Ib, II, III, IV, V, VI and VII, of which I is the southernmost and VII is the northernmost (Solantie 1988). The needed weather data, i.e. daily minimum, maximum and average temperature, and rainfall was obtained from the Finnish Meteorological Institute.

The evaluation was carried out for two apple cultivars with extreme flowering times, an early flowering cultivar Pirja and a late flowering cultivar Lobo. In reality, these cultivars are not used in all of the studied locations because of their climatic requirements (Kaukoranta et al. 2010). But, for the purpose of this study, the cultivars were considered to represent the earliest and latest apple flowering times possible for all the locations.

The start dates of flowering for the two cultivars were estimated for each year and location separately. The estimations were done using a base temperature of $5{ }^{\circ} \mathrm{C}$ (Kaukoranta et al. 2010), and by assuming the cumulative degree-days required for flowering to be 170 for Pirja and 200 for Lobo (Tahvonen et al. 2005).

The analyses were initialized one week before the estimated start date of flowering and the prevailing phenological stage at the beginning of the analysis was set as "green tip". Flowering was assumed to last for two weeks and the phenological stage in the last day of the analyses was set as "petal fall".

Maryblyt analysis was used to estimate the number of days per year during which the climatic conditions were suitable for fire blight infections, i.e. days for which the Maryblyt risk level was "infection". These are referred to as "infection days" in the text. This was done separately for the fourteen locations, the two cultivars and the twenty years studied. The data on the number of "infection days" was then used to obtain the respective predictive distributions of the number of "infection days" using Bayesian analysis, which was carried out with OpenBUGS software. Due to the very large number of zeros in the data, a zero-inflated Poisson model (e.g. Christensen et al. 2011) was assumed for $r_{i}$, the number of "infection days" per year at the ith location. Effectively, the model was then a mixture distribution: $p_{i} \times$ Poisson $\left(r_{i} \mid \lambda_{i}\right)+\left(1-p_{i}\right) \times 1_{\{0\}}\left(r_{i}\right)$, i.e. Poisson with an added point probability at zero. In BUGS language this was implemented as dpois $(\mathrm{la}[\mathrm{i}, \mathrm{k}])$ with la[i,k]<-lambda[i]* $\mathrm{u}[\mathrm{i}, \mathrm{k}]$ with binary variable $u[i, k] \sim$ dbern(p[i]) for the kth observation (year) at ith location. The mean number of "infection days" is $\mu_{i}=\lambda_{i} p_{i}$. Posterior distribution was computed with uninformative priors $p_{i} \sim U(0,1)$ and $\lambda_{i} \sim U(0,100)$. Posterior predictive distribution for $r_{i}^{\text {pred }}$ was produced in two steps: (1) sampling the posterior distribution for all parameters, then (2) sampling a predicted value $r_{i}^{\text {pred }}$ from the zero-inflated distribution using the sampled parameters. The model was run for 11000 iterations of which the last 10000 were used for further analysis. Convergence was assessed by checking the MCMC trace plots which showed no problems. The Bayesian analysis provides local predictions for the number of infection days that are conditional on the data and the model.

Areal differences in the suitability of the climate for blossom infections were studied by comparing the predictive distributions of the number of "infection days" per year of the different geographical locations separately for the two cultivars. This was done by using a Monte Carlo simulation of the number of "infection days" from the posterior predictive distribution, and by computing the probability that the expected number of "infection days" per year in a given location is higher than in any other location.

\section{Results}

The climatic conditions appear to be suitable for blossom blight infections in all the studied locations and for both the studied cultivars (Figs.2 and 3). However, this is true only for a proportion of the years. The probability of the climatic conditions being suitable for blossom infections, during at least one day in a year, was predicted to be in the range from 0.18 to 0.51 , depending on the location and cultivar considered (Table 1 ). This means that the climatic conditions were predicted to be suitable for blossom infections, during at least one day, in $18-51 \%$ of the years, depending on the location and cultivar considered. 

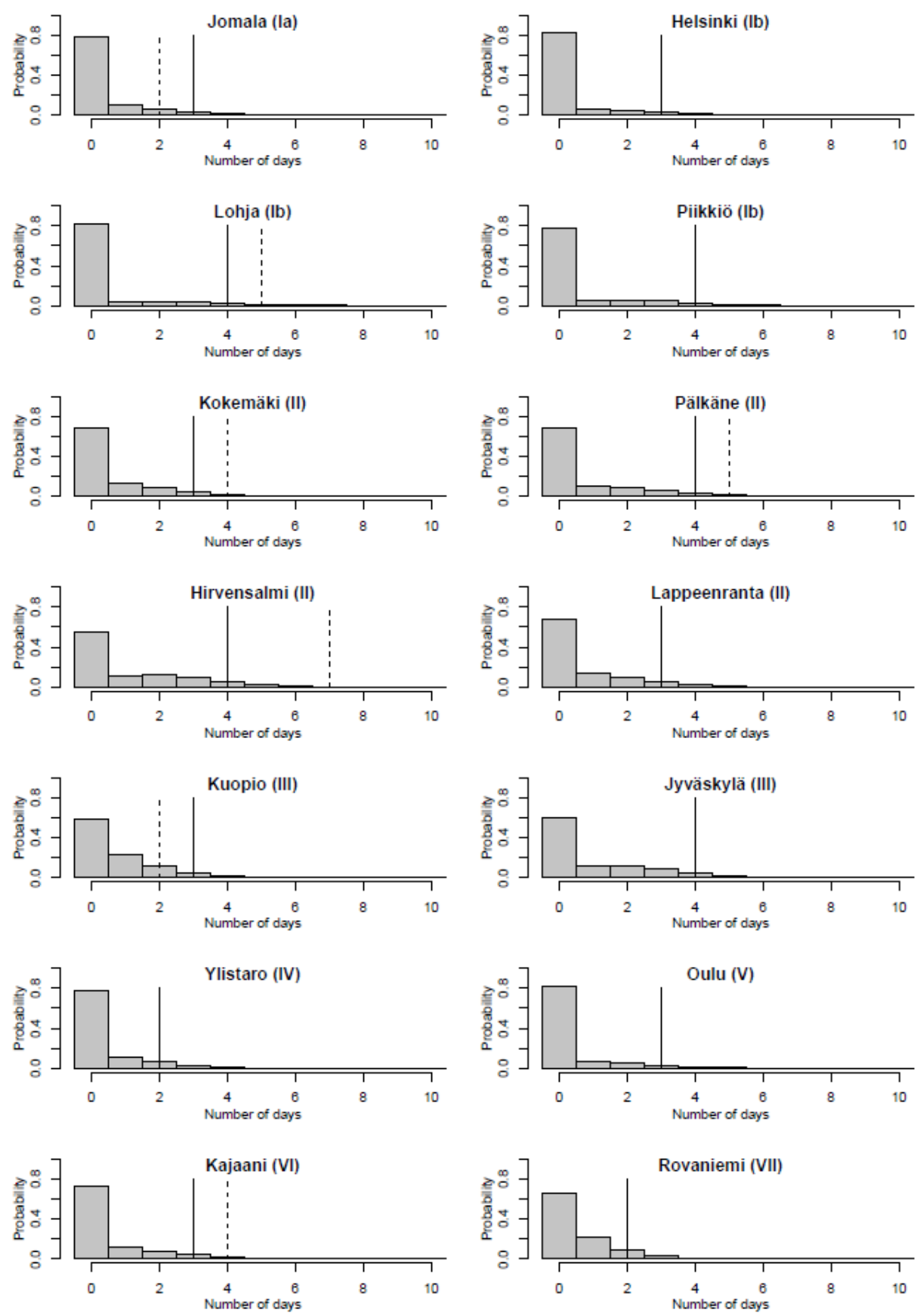

Fig. 2. The distribution of the number of "infections days" per year for the studied geographical locations for cultivar Pirja. The bars show the predictive probability distributions of "infection days"obtained with Bayesian analysis, and the solid lines indicate the respective upper bound of 95\% HPD-interval (i.e. highest posterior density interval). The broken lines indicate the highest number of "infection days" predicted for the years 1993 - 2012 by the Maryblyt analysis. (When the lines overlap, only the solid line is visible.) The plant growth zones of the locations are shown in brackets. 

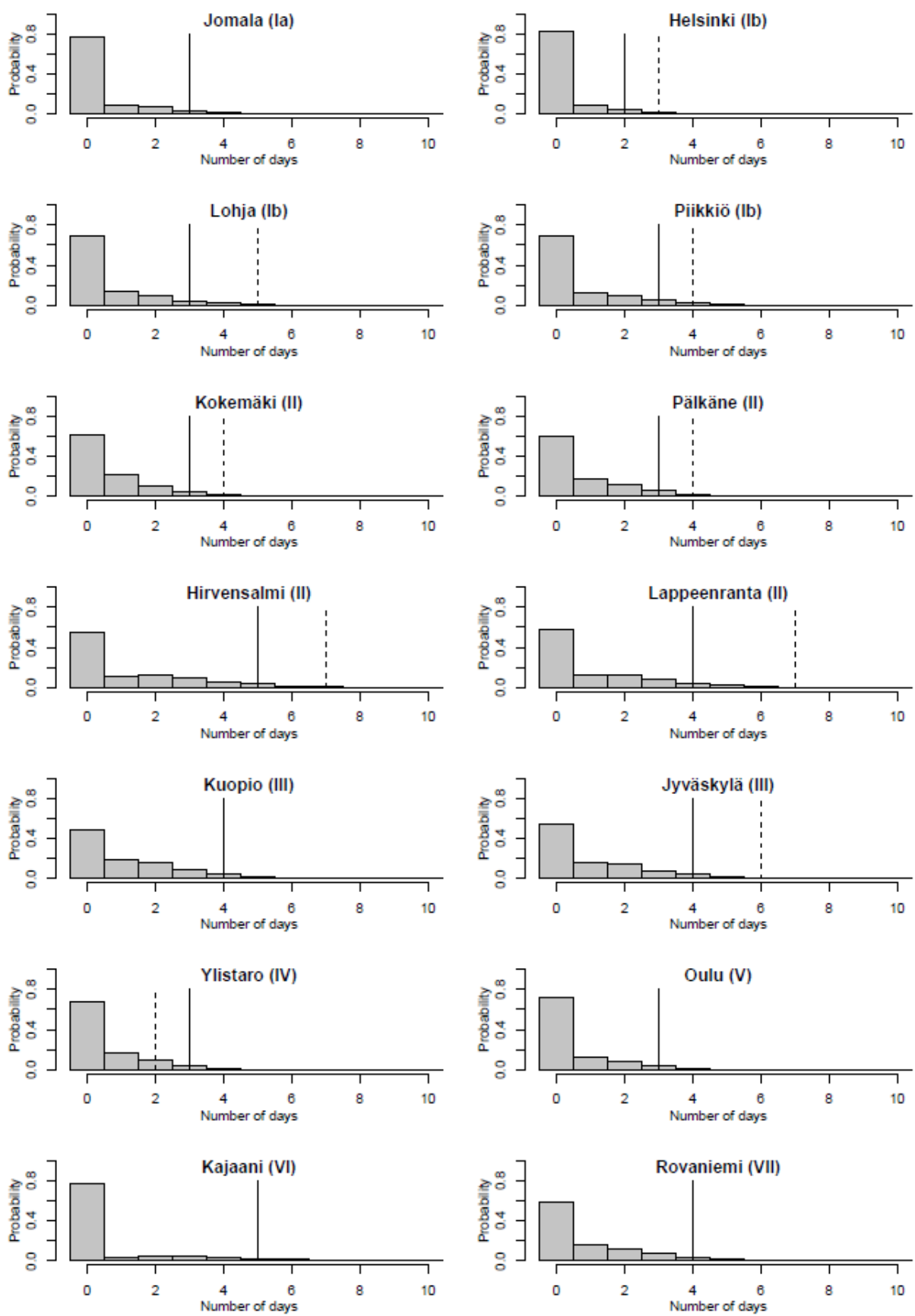

Fig. 3. The distribution of the number of "infection days" per year for the studied geographical locations for the cultivar Lobo. The bars show the predictive probability distributions of "infection days" obtained with Bayesian analysis, and the solid lines indicate the respective upper bound of 95\% HPD-interval (i.e. highest posterior density interval). The broken lines indicate the highest number of "infection days" predicted for the years 1993 - 2012 by the Maryblyt analysis. (When the lines overlap, only the solid line is visible.) The plant growth zones of the locations are shown in brackets. 
M. Marinova-Todorova et al. (2015) 24: 59-66

Table 1. The probability that the number of "infection days" in a year (D) is higher than zero in the studied geographical locations for the cultivars Pirja $\left(P_{\text {Pirja }}\right)$ and Lobo $\left(P_{\text {Lobo }}\right)$. The plant growth zones of the locations are shown in brackets.

\begin{tabular}{lcc}
\hline Location & $\mathrm{P}_{\text {Pirja }}(\mathrm{D}>0)$ & $\mathrm{P}_{\text {Lobo }}(\mathrm{D}>0)$ \\
\hline Jomala (Ia) & 0.22 & 0.24 \\
Helsinki (Ib) & 0.18 & 0.18 \\
Lohja (Ib) & 0.18 & 0.31 \\
Piikkiö (Ib) & 0.23 & 0.41 \\
Kokemäki (II) & 0.32 & 0.39 \\
Pälkäne (II) & 0.32 & 0.32 \\
Hirvensalmi (II) & 0.45 & 0.45 \\
Lappeenranta (II) & 0.32 & 0.42 \\
Kuopio (III) & 0.42 & 0.51 \\
Jyväskylä (III) & 0.41 & 0.46 \\
Ylistaro (IV) & 0.23 & 0.32 \\
Oulu (V) & 0.18 & 0.28 \\
Kajaani (VI) & 0.27 & 0.23 \\
Rovaniemi (VII) & 0.35 & 0.41 \\
\hline
\end{tabular}

The annual period during which the climatic conditions are suitable for blossom infections appears to be likely to be three days or less in most of the locations (Figs. 2 and 3). The upper bound of the 95\% HPD-interval (i.e. highest posterior density interval) of the predicted number of "infection days" varies from two to five, depending on the location and cultivar considered (Figs. 2 and 3 ). This means that in $95 \%$ of the years the period that is suitable for blossom infections was predicted to be equal to or less than two to five days, depending on the location and cultivar considered.

The length of the period during which climatic conditions are suitable for blossom infections varies between the studied geographical locations (Figs. 2 and 3). Yet, there are no clear differences between the plant growth zones, and the differences between locations are not consistent between the studied apple cultivars. However, the suitable period seems to be longer for both cultivars in central Finland (Hirvensalmi and Jyväskylä) than in the southernmost parts of the country (Jomala and Helsinki) (Table 2). The probability that the expected number of "infection days" per year in a given location is higher than in any other location is highest for Hirvensalmi for both Pirja and Lobo, and lowest for Jomala and Helsinki, for Pirja and Lobo respectively (Table 2).

Table 2. The probability that the expected number of "infection days" per year $\left(\mu_{\mathrm{i}}\right)$ in the considered location $(i)$ is higher than in any other location $(\max (\mu))$ for cultivars Pirja $\left(\mathrm{P}_{\text {Piria }}\right)$ and Lobo $\left(\mathrm{P}_{\text {Lobo }}\right)$. The plant growth zones of the locations are shown in brackets.

\begin{tabular}{lcc}
\hline Location & $\mathrm{P}_{\text {Pirja }}\left(\lambda_{\mathrm{i}}=\max (\mu)\right)$ & $\mathrm{P}_{\text {Lobo }}\left(\lambda_{\mathrm{i}}=\max (\mu)\right)$ \\
\hline Jomala (Ia) & 0.005 & 0.006 \\
Helsinki (Ib) & 0.015 & 0.001 \\
Lohja (Ib) & 0.040 & 0.009 \\
Piikkiö (Ib) & 0.054 & 0.017 \\
Kokemäki (II) & 0.031 & 0.006 \\
Pälkäne (II) & 0.078 & 0.029 \\
Hirvensalmi (II) & 0.462 & 0.383 \\
Lappeenranta (II) & 0.018 & 0.134 \\
Kuopio (III) & 0.031 & 0.175 \\
Jyväskylä (III) & 0.223 & 0.108 \\
Ylistaro (IV) & 0.006 & 0.005 \\
Oulu (V) & 0.010 & 0.006 \\
Kajaani (VI) & 0.021 & 0.073 \\
Rovaniemi (VII) & 0.006 & 0.049 \\
\hline
\end{tabular}




\section{Discussion}

The climatic conditions in Finland appear to be suitable for fire blight infections on apple in all the parts of the country that were considered in this study, from the Aland Islands in the south up to Rovaniemi in the north. Based on epidemiological modelling and historical weather data for 20 years (1993 - 2012), the climatic conditions were predicted to be suitable for blossom infections in $18-51 \%$ of the years, and the annual period of suitable conditions was predicted to last up to two to five days, depending on the location and apple cultivar considered.

The predicted length of the period suitable for blossom infections varied between the studied geographical locations and cultivars. Although no consistent pattern in the geographical variation could be detected the suitable period was predicted to be longer in some locations in Eastern and Central Finland (Hirvensalmi and Jyväskylä) than in those in the southernmost parts of the country (Jomala and Helsinki). However, drawing conclusions about countrywide variation in the suitability of the climate based on these results is dubious, because it is not known how well the included locations represent the wider surrounding area with respect to the relevant climate parameters.

The epidemiological model used in this study, i.e. Maryblyt has been successfully used to predict infection events in areas where E. amylovora is present, mainly in North America (e.g. Bonn and Leuty 1993, Bonn 1996, Lightner et al. 1999), but also in Poland (Sobiczewski and Berczynski 1993), Italy (Bazzi et al. 1996), Germany (Moltmann 2006), Switzerland (Vogelsanger et al. 2006), Bulgaria (Bobev and Lightner 2008), New Zealand (Couk et al. 1996) and Egypt (Abol Maatey et al. 2002). Maryblyt has also been used to assess the probability of fire blight infections in areas where the disease is not present (Giayetto and Rossini 2011). However, the accuracy of the predictions is naturally more uncertain in areas where they have not been tested in practice.

Some inadequacies of the data used in this study may affect the results. In reality, the climatic conditions in Finland may be suitable for blossom infections more often and for longer periods of time annually than predicted in this study. This is because the weather data used in the analysis did not cover any other wetting events but rain. Wetting caused by dew or fog was not taken into account, although these may be sufficient to enable blossom blight infections (Steiner 1990a, Smith and Pusey 2011).

The apple cultivars considered in this study are not used in all the studied geographical locations, because of their climatic requirements (Kaukoranta et al. 2010). Hence, the analyzed situation does not mimic reality exactly. This is not considered as a major weakness, since the start dates of flowering of different apple cultivars are normally only a couple of days apart, due to the rather similar degree-day requirements of the different cultivars (Tahvonen et al. 2005). For the purpose of this study, the cultivars used were considered to represent the earliest and latest possible apple flowering times for all the locations. However, the results may be less accurate for the northern locations where neither of the studied cultivars is used.

The results of this study indicate that fire blight can cause epidemics in all apple growing areas in Finland. Fortunately, the highest likelihood for epidemics doesn't seem to be in the important apple growing areas, which are the Aland Islands and South and South-Western Finland (Varsinais-Suomi and Uusimaa). About $80 \%$ (527 ha) of the total apple production area is located in these areas (Tike 2014). In other parts of the country apple is grown mostly in home gardens. Only about 7\% ( $45 \mathrm{ha}$ ) of the total apple production area is located in Eastern and Central Finland (Etelä-Savo and Keski-Suomi), where the likelihood for epidemics is predicted to be the highest (Tike 2014).

The fact that fire blight was recently detected on pear trees in the Aland Islands (Evira 2014) neither supports nor compromises the results of this study. This is because the results of this study are not valid for pear, since the development of blossom blight on pear differs from that on apple to such an extent that they are treated with separate models in Maryblyt. For the same reason the results are not entirely applicable for ornamental hosts either. However, the results indicate that epidemics on ornamental hosts are likely to be possible in all parts of the country.

Based on these results the official surveys that are carried out to confirm the absence of fire blight in Finland cannot be targeted only to some parts of the country. If the primary aim of the surveys is to detect possible fire blight invasions as early as possible, it may be advisable to target the surveys especially to the areas in Central Finland where the climatic conditions seem to be most favourable to development of epidemics (Hirvensalmi, Jyväskylä, Kuopio and Lappeenranta). However, possible areal differences in the probability of pest entry also have to be taken into account when planning survey activities. In Finland the introduction of fire blight with apple plants is probably most likely in the important apple growing areas located in the Aland Islands and South and South-Western Finland. Likewise, introduction with ornamental hosts is probably more likely in South and South-Western Finland due to the higher human population density in those regions. However, without quantitative estimates of the areal differences in the probability of pest entry it is not possible to assess whether the differences in the probability of entry would overweigh the differences in the suitability of the climate. 


\section{References}

Abol Maatey, S.M., Medany, M.A., Abou Hadid, A.F., El Ghafar, N.Y.A. \& Elewa, I.S. 2002. The use of climatic data for integrated management of pears: forecasting fire blight. Acta Horticulturae 596: 523-527.

Bazzi, C., Merighi, M., Stefani, E., Gambin, E., Saccardi, A., Calzolari, A. \& Perugini, C. 1996. Maryblyt 4.2: Prediction of Fire blight outbreaks in Italy (Po Valley). Acta Horticulturae 411: 163-172.

Billing, E. 1996. BIS95, an Improved Approach to Fire Blight Risk Assessment. Acta Horticulturae 411: 121-126.

Bobev, S. \& Lightner, G. 2008. Simulative analyses of apple and pear bloom risks in Bulgaria with Maryblyt 4.3. Acta Horticulturae 793: 465-471.

Bonn, W.G. 1996. Maryblyt 4.2: Evaluating the program for prediction of blossom blight of apple and pear. Acta Horticulturae 411: 173-175.

Bonn, W.G. \& Leuty T. 1993. An assessment of the Maryblyt ${ }^{\mathrm{TM}}$ computer program for prediction of fire blight in Ontario, Canada. Acta Horticulturae 338: 145-152.

Bonn, W.G. \& van der Zwet, T. 2000. Distribution and economic importance of fire blight. In: Vanneste, J.L. (ed.). Fire blight: the disease and its causative agent, Erwinia amylovora. Wallingford, UK: CABI Publishing. p. 37-53.

Christensen, R., Johnson, W., Branscum, A. \& Hanson, T.E. 2011. Bayesian ideas and data analysis An introduction for scientists and statisticians. Boca Raton, USA, CRC Press. $498 \mathrm{p}$.

Couk, S.C., Bedford, R.J., Hutchings, S.O., Cole, L. \& Voyle, M.D. 1996. Evaluation of the Maryblyt ${ }^{\mathrm{TM}}$ model for predicting fire blight blossom infection in New Zealand. Acta Horticulturae 411: 109-113.

EPPO 2013. Erwinia amylovora present in Russia. EPPO Reporting Service. 1: 2.

EPPO 2014. First report of Erwinia amylovora in Estonia. EPPO Reporting Service 1: 6.

Evira 2014. Fireblight spreads to a pear plantation in Åland. Accessed 8 December 2014. http://www.evira.fi/portal/en/plants/ current+issues/?bid=4069.

Giayetto, A. \& Rossini, M. 2011. Prediction of Symptoms Occurrence of Fire Blight (Erwinia amylovora) by the MARYBLYT ${ }^{\mathrm{TM}}$ Program in Rio Negro, Argentina. Acta Horticulturae 909: 517-520.

Kaukoranta, T., Tahvonen, R. \& Ylämäki, A. 2010. Climatic potential and risks for apple growing by 2040. Agricultural and Food Science 19: 144-159.

Kõiva, E. 2003. Possibility of appearance of fire blight Erwinia amylovora in Estonia. Agronomy Research 1: 145-160.

Lightner G.W, van der Zwet, T. \& Steiner, P.W. 1999. Fifteen year summary of the efficacy of Maryblyt prediction system on apple in West Virginia (1984-1998). Acta Horticulturae 489: 445-447.

Moltmann, E. 2006. Ten years summary of fire blight prediction in South-West Germany (1994 - 2003). Acta Horticulturae 704 : 177-181.

Norin, I. 1987. Växtskyddsåret 1986 - trädgård. Växtskyddsnotiser 51: 38-40.

Sletten, A. 1990. Fire blight in Norway. Acta Horticulturae 273: 37-40.

Sletten, A. \& Rafoss, T. 2007. Fire blight in Norway. An assessment of the plant health risk for the plant disease fire blight in Norway. Bioforsk Rapport 2. Ås, Norway. 51 p.

Smith, T.J. 1993. A Predictive Model for Forecasting Fire Blight of Pear and Apple in Washington State. Acta Horticulturae 338 : 153-157.

Smith, T.J. \& Pusey, P.L. 2011. CougarBlight 2010, a significant update of the CougarBlight fire blight infection risk model. Acta Horticulturae 896: 331-336.

Sobiczewski, P. \& Berczynski, S. 1993. Evaluation of Maryblyt for prediction of fire blight on apples in Poland. Acta Horticulturae 338: 167.

Solantie R. 1988. Modification of the climatic zones for fruit trees and woody ornamental plants in Finland. Sorbifolia 19: 124-126.

Steiner, P. 1990a. Predicting apple blossom infections by Erwinia amylovora using the Maryblyt model. Acta Horticulturae 273: 139-148.

Steiner, P. 1990b. Predicting canker, shoot and trauma blight phases of apple fire blight epidemics using the Maryblyt model. Acta Horticulturae 273: 149-158.

Tahvonen, R., Kinnanen, H. \& Ylämäki, A. 2005. Onnistunut pölytys on runsaan omenasadon edellytys. Koetoiminta ja käytäntö 62: 12. (in Finnish).

Thomson, S.V. 2000. Epidemiology of fire blight. In: Vanneste, J.L. (ed.). Fire blight: the disease and its causative agent, Erwinia amylovora. Wallingford, UK: CABI Publishing. p. 9-36.

Tike 2014. Puutarhatilastot 2013. Information Centre of the Ministry of Agriculture and Forestry Tike. Finland. 27 p. http://www. maataloustilastot.fi/e-lehti-puutarhatilastot-2013/index.html Accessed 10 February 2015 (in Finnish)

Vogelsanger, J., Schoch, B., Vignutelli, A., Baroffio, C., Bunter, M., Holliger, E. \& Duffy, B. 2006. Monitoring fire blight on wild hosts and ornamentals. Acta Horticulturae 704: 197-201. 